\title{
The Cambridge History of Latin American Women's Literature
}

Rodríguez, Ileana y Mónica Szurmuk (Eds.) (2015). Nueva York: Cambridge University Press, 666 pp.

@ María José Punte

UCA

Este volumen publicado en inglés por la Universidad de Cambridge es el resultado de un trabajo tan exhaustivo como ambicioso. En principio, se propone como una herramienta para la labor crítica del ámbito académico dedicado a las letras latinoamericanas. En cuanto a los resultados, se destaca por ser una apuesta a reconsiderar un enorme corpus textual que había sido claramente obliterado por miradas demasiado habituadas a una aproximación canónica de la literatura. En todo caso, supone volver a las textualidades que llevan la marca del género femenino en tanto que productoras o hacedoras. El libro se constituye en un mapa que conduce a los lectores y lectoras a territorios en parte todavía ignotos. Uno de los objetivos de esta historia de la literatura de mujeres en América Latina es ofrecer una cartografía que termina siendo tan vasta como sorprendente. La sorpresa emerge ante la cantidad de mujeres de letras que forman parte de un acervo que ya ha sido algo transitado. Muchas de ellas son bien conocidas tanto por los y las lectores como por la crítica. Pero muchas otras aún perduran replegadas en los márgenes que han dejado libres las lecturas y las enseñanzas institucionalizadas. Este mapa, entonces, adquiere volúmenes y se expande en varias direcciones, porque su rasgo definitorio es poner en vinculación, más que mostrar.

Algunas de las imágenes que emergen en la introducción a partir de las palabras de las editoras lleana Rodríguez y Mónica Szurmuk, evocan al hueco y a la herida, fruto tanto de la negligencia como de la negación. Remiten más a la falta o carencia que a la superproducción o el exceso. En cierto modo hacen pensar en la obra de la artista plástica brasileña Adriana Varejão, especialmente en aquellos cuadros que dejan entrever carne tras las grietas de los azulejos portugueses o las rasgaduras de los mapas. No se trata meramente de hacer salir siglos de escrituras a cargo de sujetos femeninos que habían quedado escondidos en armarios y en desvanes, en tantos cuartos propios. Lo que provoca este volumen es la apertura bajo la forma del resquebrajamiento. Abrir fisuras, ampliar las existentes, sobre un edificio cuidadosamente montado durante una temporalidad, la de la construcción de este territorio que llamamos América, y que se devela una vez más como un espacio textual. Implica repensar el continente desde una miríada de voces. Las mujeres siempre estuvieron allí, durante la conquista, con sus cuotas de exterminio y de utopía, así como durante la construcción de las naciones modernas. Hicieron revoluciones, construyeron las ciudades letradas, armaron sus propias redes tanto internas como externas. Algo queda muy claro al terminar de leerlo y es que nunca dejaron de trabajar.

El resultado más que panóptico o expositivo es el de articular una mirada crítica hacia la historia contada hasta el presente. Las opciones adoptadas por los diversos aportes para encarar sus respectivos campos son, por momentos, divergentes. Como bien sintetizan las editoras, hay ensayos más informativos sobre mujeres que habían sido ignoradas por el archivo y que ofrecen una mirada feminista sobre la historia cultural. Otros ensayos abren debates sobre categorías que atraviesan el tiempo y que tendieron a proponerse como oposiciones: lo local y lo global, el centro y la periferia, lo femenino y lo masculino. Por último, ellas se refieren a una tercera modalidad ensayística dentro del conjunto que ofrece piezas más inventivas, ocupadas en mapear tanto las raíces como las travesías de estas conciencias formadas desde el feminismo, que proponen nuevas significaciones a conceptos viejos, tales como sensibilidad y juicio, localizaciones 
transoceánicas, criminalidad, herencia, sexualidad. En ese sentido es que termina siendo un libro que reflexiona sobre lo literario y la literatura, en la vinculación de la letra con lo oral, con la creatividad de las mujeres a la hora de materializar nuevos géneros y de exceder los roles preestablecidos.

La estructura del volumen se ciñe a un orden diacrónico por lo que se divide en cuatro partes que despliegan esta historia desde la sociedad colonial, pasando por la sociedad criolla y la construcción de la nación, hasta llegar al siglo XX y al momento contemporáneo, al que se define como el del sistema de mundo global.

La primera parte, dedicada al período colonial y al mundo indígena, evoca la noción de tejido no solo como una referencia a otros tipos de escritura relegados por la concepción occidental de la letra y de lo letrado, los quipus. Implica una manera de pensar críticamente qué es el archivo (Santa Arias), en tanto que forma androcéntrica de encarar el corpus textual, del cual se cuestiona su mirada ya "generizada". En esta sección se discutirá desde distintos escorzos qué significa la letra a partir de nociones establecidas como la figura de la "mujer de letras", que resulta obvia en la ya canónica de Sor Juana Inés de la Cruz (Beatriz Colombi). Esto, que en realidad plantea la cuestión espinosa de cómo funciona la vinculación entre lo oral y lo escrito, y de la escritura con otros tipos de artefactos materiales, y que se pone en evidencia en las formas de reclamo de las mujeres de la elite Inca, las “doñas” o "ñustas" (Rocío QuispeAgnoli). El recorrido lleva por las diversas maneras en que se construyeron las subjetividades femeninas durante el período colonial, subrayando el papel de mediadoras culturales que les competió a las mujeres. Esta va desde la figura de la traductora/traidora encarnada por la Malinche, hasta llegar a las monjas, en el emblemático emergente de Sor Juana, pero que incluye ejemplos menos conocidos (Mónica Díaz). También están las cronistas junto con variantes no tenidas en cuenta que se construyen desde la palabra, sea mediante textos de carácter auto-etnográfico o de otros tipos de testimonio (Valeria Añón). En todos los casos se ponen en acto estrategias textuales para escapar al control social y discursivo, escenificado en espacios materiales como los conventos que también cobraban forma en aquello que las mujeres podían o debían decir. Las estrategias retóricas que las mujeres adoptan van del silencio a la demanda, pero sobre todo implican formas de desviación.

La segunda parte se concentra en los proyectos de construcción de la nación en las sociedades criollas, en un período que va de 1850 a 1930. La base para pensar este período ya había sido colocada por críticas como Doris Sommer, quien había hecho resaltar este papel de colaboradora adjudicado a las mujeres, que termina exhibiendo su sesgo de organización de género y de clase. Este nuevo recorrido apunta sobre todo a hacer visible otra trama, que es la de las redes construidas tanto en el eje que va de norte a sur, como más allá del Atlántico. Los espacios así resultantes dan cuenta de otras morfologías. El ejemplo de Brasil, una terra incognita por antonomasia, obliga a pensar en los modos en que se tendió a construir el canon, con su excesivo acento en la escritura y la cultura universitaria (Rita Terezinha Schmidt). Los territorios adquieren nuevas densidades al tener en cuenta no solo la irrupción del elemento sonoro, los ruidos (Gwen Kirkpatrick), sino también la gravitación de los cuerpos en el espacio público que se visibiliza de maneras a veces inesperadas (Francine Masiello). Esta sección abre y cierra con la cuestión de las mujeres en tanto que trabajadoras y también como viajeras, muy alejadas de un modelo de lo estático (Mónica Szurmuk y Claudia Torre); y de la transnacionalidad de las escritoras que echan lazos no solo hacia Europa sino también en el eje que se extiende entre el norte y el sur (Ana Peluffo). De la continentalidad a la insularidad, esta sección cierra con la literatura de las Antillas Hispánicas (Catherine Davies), dando cuenta de una actividad literaria por parte de las mujeres, tan copiosa como frenética.

Afincada en el siglo XX y por razones obvias la más extensa, la tercera parte toma en cuenta la aceleración que sufre el período histórico en términos de desarrollos, pero también la violencia que experimentan en particular las mujeres en esos contextos. En el siglo XX las mujeres ya atraviesan todos los debates y cambios sociales, desde la revolución a la militancia, desde los desplazamientos a las migraciones. Un siglo que abre con revoluciones en las que el papel de las mujeres, no del todo reconocido por la institución literaria, fue insoslayable. Valgan como ejemplo los movimientos insurgentes y las revoluciones en México (Maricruz Castro Ricalde), Cuba y Nicaragua (Parvathi Kumaraswami). Paradójicamente, los sistemas literarios parecen generar movimientos centrífugos que buscan empujar a las mujeres hacia los márgenes, como se ve en las vanguardias (Vicky Unruh) o el así llamado boom (María Rosa Olivera-Williams). Las escritoras, por su parte, desarrollan estrategias de resistencia, apostando a formas disidentes de cosmopolitismo (Gabriel Giorgi y Germán Garrido), líneas de fuga para la poesía (Karen Benavente), nuevos modos de vivir entre culturas en el ejemplo de escritoras mexicanas (Debra Castillo), debido a las 
migraciones y los exilios políticos (María Inés Lagos, María Josefina Saldaña-Portillo). La hibridación de las formas va de la mano de esta capacidad de vivir más allá de las fronteras que se produce sea por necesidad o por elección. La riqueza cultural del continente obliga a poner el foco en áreas con características propias como lo son el Caribe tanto anglo como francófono Kanika Batra), América Central (Nicole Caso), la región andina y la escritura de las mujeres mayas (Núria Vilanova, Arturo Arias). Se trata de un siglo cuyo final recrudece la violencia que tiene como blanco específico a las mujeres. De esto da cuenta la literatura del testimonio, uno de los avatares de la escritura autobiográfica y del giro subjetivo (Nora Strejilevich), así como otros tipos de escritura que trabajan sobre la memoria (Michael J. Lazzara). La violencia adopta dos figuras muy específicas como son la del femicidio, una que por su parte tiene su propia genealogía (Jean Franco), y una nueva que sirve para pensar la violencia, que es la del niño muerto (Nora Domínguez). Hacia fines del siglo XX, si hay algo que estas escrituras dejan en claro es cómo se desdibuja una idea homogénea de Nación. Lo que emerge es otro dibujo, uno que se encontraba subterráneo.

La última sección piensa desde lo contemporáneo a estas construcciones subjetivas que aparecen en el entramado del neoliberalismo, el del sistema de mundo global. En la cuarta parte, se perciben nuevamente estas diferentes densidades que van desde la levedad a la abyección, en virtud de una mayor o menor sujeción a los deseos del mercado (Beatriz González-Stephan y Carolyn Fornoff); pero también al mayor o menor acatamiento de los imperativos que rigen la sexualidad y las nuevas formas de agenciamiento. En suma, se debe tanto a las reconfiguraciones de género como del mundo del trabajo. Más allá del archivo, ahora de lo que se trata es de pensar en términos de sistema, para visualizar el campo literario desde las tendencias: de lo residual a lo arcaico, de lo visible a lo sintomático. Así como es posible seguir la pista a determinadas genealogías poéticas que apuestan a lo perverso, en sentido de la desviación programática de lo normativo (Laura M. Martins), también proliferan las transgresiones formales al objeto canonizado como libro para producir nuevos artefactos literarios (Marcy Schwartz). Si bien parece inevitable concluir el volumen y esta sección con una reflexión sobre los modos en que hoy toma cuerpo la violencia hacia las mujeres (Héctor Domínguez Ruvalcaba y Patricia Ravelo Blancas), lo cual parecería estar hablando de la imagen de "implosión" de la que nos alertan las editoras, la centralidad de las mujeres en el sistema de mundo presente se vislumbra indeleble en ese "mapa nocturno" al que remite Mary Louise Pratt para concluir. La metáfora sirve para pensar el trabajo escriturario de las mujeres durante varios siglos: si se oscurece la escena principal, nos recuerda Pratt, aún se pueden ver esas luces de mujeres que trabajan por la noche. 
